EDUR • Educação em Revista. 2021; 37:e25641

DOI: http://dx.doi.org/10.1590/0102-469825641

() (1) https://creativecommons.org/licenses/by/4.0/

ARTIGO

\title{
POR UMA AGENDA CURRICULAR DEMOCRÁTICA COM FOCO NA INOVAÇÃO EDUCATIVA PARA O BRASIL
}

\author{
ROBERTO RAFAEL DIAS DA SILVA ${ }^{1}$ \\ ORCID: http://orcid.org/0000-0001-6927-3435
}

\begin{abstract}
RESUMO: O presente ensaio realiza uma breve revisão dos estudos pedagógicos brasileiros, publicados em meados do século XX, visando construir marcos referenciais para uma agenda curricular democrática com foco na inovação educativa. Tomam-se como dimensão contextual os paradoxos da democracia, amplamente descritos pelas teorizações sociais contemporâneas, associados à preocupação de elaborar alternativas pedagógicas em um cenário de intensificação das políticas neoliberais e neoconservadoras no Brasil. Aposta-se no alargamento conceitual da inovação educativa, justaposto aos marcos de uma governança escolar democrática, ingressando na luta política em torno de seus significados. A promoção de oportunidades aos estudantes, a dialogicidade como conteúdo e método e a seleção de conhecimentos escolares relevantes são referências conceituais, buscadas nos escritos de Anísio Teixeira, Paulo Freire e Demerval Saviani, que servirão de base para a reconstrução de práticas curriculares democráticas no Brasil. Por tradições teóricas heterogêneas, tais autores oferecem possibilidades críticas e criativas para a reconstrução da escola democrática em nosso país.
\end{abstract}

Palavras-chave: escola, currículo, inovação educativa, democracia, Brasil.

\section{FOR A DEMOCRATIC CURRICULAR AGENDA FOCUSED ON EDUCATIONAL INNOVATION FOR BRAZIL}

\begin{abstract}
This essay briefly reviews Brazilian pedagogical studies published in the mid-twentieth century, with the aim of constructing benchmarks for a democratic curriculum agenda focused on educational innovation. It takes as contextual dimension the paradoxes of democracy, widely described by contemporary social theorizations, associated with the concern of elaborating pedagogical alternatives in a scenario of intensification of neoliberal and neoconservative policies in Brazil. We bet on the conceptual widening of educational innovation, juxtaposed to the frameworks of democratic school governance, entering the political struggle around its meanings. The promotion of opportunities for students, dialogicity as content and method, and the selection of relevant school knowledge are conceptual references, sought in the writings of Anísio Teixeira, Paulo Freire and Demerval Saviani, that will serve as a basis for the reconstruction of democratic curriculum practices in Brazil. Through
\end{abstract}

\footnotetext{
${ }^{1}$ Universidade do Vale do Rio dos Sinos. São Leopoldo, RS, Brasil. <robertods@unisinos.br>
} 
heterogeneous theoretical traditions, these authors offer critical and creative possibilities for the reconstruction of the democratic school in our country.

\section{POR UNA AGENDA CURRICULAR DEMOCRÁTICA ORIENTADO A LA INNOVACIÓN EDUCATIVA PARA BRASIL}

RESÚMEN: Este ensayo realiza una breve revisión de los estudios pedagógicos brasileños, publicados a mediados del siglo XX, con el objetivo de construir puntos de referencia para una agenda curricular democrática con enfoque en la innovación educativa. Las paradojas de la democracia, ampliamente descritas por las teorías sociales contemporáneas, se toman como una dimensión contextual, asociada a la preocupación por desarrollar alternativas pedagógicas en un escenario de intensificación de las políticas neoliberales y neoconservadoras en Brasil. Nos enfocamos en la expansión conceptual de la innovación educativa yuxtapuesta a los hitos de la gobernabilidad escolar democrática, sumándonos a la lucha política en torno a sus significados. La promoción de oportunidades para los estudiantes, la dialogicidad como contenido y método y la selección de conocimientos escolares relevantes son referencias conceptuales, buscadas en los escritos de Anísio Teixeira, Paulo Freire y Demerval Saviani que servirán de base para la reconstrucción de prácticas curriculares democráticas en Brasil. Por tradiciones teóricas heterogéneas, estos autores ofrecen posibilidades críticas y creativas para la reconstrucción de la escuela democrática en nuestro país.

Palabras clave: escuela, curriculum, innovación educativa, democracia, Brasil. 


\title{
INTRODUÇÃO
}

\begin{abstract}
Em certo sentido, a tarefa diante de nós é reinventar uma linguagem para a educação - uma linguagem que responda aos desafios teóricos e práticos com que nos defrontamos hoje em dia (BIESTA, 2013, p. 30).
\end{abstract}

A julgar pelas aparências, a democracia é uma flor frágil (GIDDENS, 2000, p. 90).

Enquanto escrevíamos o presente ensaio pedagógico, experimentamos tempos paradoxais: ao mesmo tempo que assistimos a um crescente declínio da confiança nos Estados e nos modos de vida democráticos, proliferam-se novos modelos pedagógicos proponentes de uma inovação educativa. Tal condição resulta paradoxal devido ao fato de que, historicamente, a promoção de arranjos curriculares inovadores sempre esteve acompanhada da defesa de modos de vida democráticos, conforme assistimos nos movimentos renovadores da primeira metade do século XX. Como podemos pensar em práticas curriculares inovadoras em um contexto de declínio da confiança nos modos de vida democráticos? Ou ainda: que referências buscaremos para a composição de uma agenda curricular democrática que possa nos conduzir na direção da inovação educativa no Brasil deste início de século XXI?

A literatura educacional, há bastante tempo, tem sinalizado para as dificuldades das instituições escolares em se moverem na busca por alternativas organizativas (FULLAN, 2002; SANCHO-GIL; HERNANDEZ, 2011; MARCELO, 2013). Sejam os estudos sobre as culturas escolares (VIÑAO, 2000), sejam aqueles em torno de uma gramática da escolarização (TYACK; CUBAN, 2001), esboça-se como um consenso entre os pesquisadores do campo que esta instituição tem dificuldade em romper determinados modelos organizativos que foram sendo construídos historicamente. De forma ambivalente, torna-se fortalecida, hodiernamente, a argumentação em torno de um declínio da própria escola e de sua função pública na direção de uma sociedade de aprendentes vitalícios (POPKEWITZ, 2009; BIESTA, 2014; BALL, 2016).

Nessa direção, em seus estudos recentes, o filósofo Gert Biesta (2013; 2016) tem nos provocado a pensar acerca de um declínio da "linguagem da educação" em detrimento de uma "nova linguagem da aprendizagem". Os modelos educacionais erigidos na Modernidade, dentre os quais a Bildung era um de seus pilares, têm sido substituídos por uma perspectiva que atribui centralidade aos processos de aprendizagem. A emergência de novas teorias da aprendizagem, o pós-modernismo, a gramática da aprendizagem vitalícia e a própria erosão do Estado de bem-estar social contribuíram para o delineamento de novos modos de pensar a escolarização contemporânea. Em sua perspectiva, as noções de democracia e cidadania, por exemplo, tendem a se distanciar dos debates públicos sobre as finalidades da escola e das possibilidades de aprendizagem dos estudantes nos variados países.

De acordo com Biesta (2013), a nova linguagem da aprendizagem torna-se problemática porque "tem facilitado uma nova descrição do processo da educação em termos de uma transação econômica" (p. 37). Assim, o estudante é um potencial consumidor que precisa ter atendidas as suas necessidades, enquanto o professor e a escola precisam ofertar a melhor mercadoria. A educação enquanto processo de transação econômica sugere uma estrutura "em que as únicas questões que podem ser significativamente propostas são questões técnicas, isto é, questões sobre a eficiência e a eficácia do processo educacional" (p. 41). Em decorrência dessa compreensão, as questões acerca dos conteúdos e dos objetivos educacionais precisam ser revitalizadas e, permanentemente, colocadas em discussão.

Numa escala mais ampla, as questões sobre o conteúdo e o objetivo da educação são, portanto, questões fundamentalmente políticas. Deixar uma resposta a essas questões a cargo das forças do mercado - e todos sabemos como os mercados podem ser manipuladores para assegurar seu próprio futuro - priva-nos da oportunidade de ter uma voz democrática na renovação educacional da sociedade (BIESTA, 2013, p. 43).

Avançando na composição do presente estudo, importa salientar que os debates em torno das possibilidades de uma educação democrática no Brasil têm-se constituído como um campo controverso e, cada vez mais, indispensável. No âmbito dos Estudos Curriculares, estudos como os de Antônio Flávio Moreira (2012), Lucíola Santos (2007) e Alfredo Veiga-Neto (2002), por vertentes diferentes, apregoavam a pertinência e a atualidade de se revisitar o pensamento curricular brasileiro 
desde outras perspectivas. Com Moreira (2012), o campo sentiu-se desafiado a reposicionar as articulações entre conhecimento escolar e cultura mais ampla, por meio de seus princípios para as políticas e decisões curriculares. A busca por novas geometrias e outras formas de reação crítica ao pensamento curricular dominante advém de um relevante estudo do professor Veiga-Neto (2002). Todavia, a crítica mais contundente, nos marcos de uma escola democrática, encontramos em Santos (2007) ao denunciar as dificuldades do campo dos Estudos Curriculares, desde o fim da década de 1990, em contribuir com as demandas efetivas das escolas públicas brasileiras. A pesquisadora brasileira argumentava ainda que o referido campo de estudos, ao se ampliar em seus focos investigativos e perspectivas epistemológicas, se distanciara das questões escolares.

Inscrevemos nossa perspectiva de trabalho curricular nesta tradição, qual seja: aquela longa tradição crítica de pedagogias que produzem resistência às desigualdades e apostam no potencial democrático do conhecimento na escolarização pública (SILVA, 2019). Importante salientar, então, que construímos nossos argumentos assentados em três pressupostos orientadores, a saber: a) a opção pela educação básica como objeto analítico privilegiado; b) o pluralismo teórico e metodológico na composição do estudo, dialogando sistematicamente com o campo dos Estudos Curriculares; c) o reconhecimento das demandas por inovação e a crítica aos modelos curriculares derivados do neoliberalismo. Em tais condições, defendemos a promoção de leituras críticas do processo de implementação dos currículos escolares contemporâneos, justaposta a uma abordagem propositiva das práticas curriculares democráticas em contextos variados.

Para a composição do estudo teórico, levamos em consideração a intensa proliferação de estudos curriculares publicados no Brasil e na América Latina, na última década, priorizando os estudos sociológicos sobre a questão. Para tanto, proporemos a construção de uma agenda curricular democrática que aceite as demandas advindas dos movimentos que apregoam a inovação educativa; entretanto, faremos algumas digressões históricas para buscar referências nos escritos pedagógicos brasileiros publicados em meados do século XX. Além de revisitar nossa tradição crítica - relendo Anísio Teixeira, Paulo Freire e Demerval Saviani, leituras situadas em itinerários argumentativos diferentes -, nosso compromisso está em sistematizar algumas de suas contribuições para o pensamento curricular brasileiro que seguem atuais e pertinentes para a reconstrução de nossos debates sobre as escolas democráticas em nosso país.

\section{REVISITANDO O CAMPO DOS ESTUDOS CURRICULARES: CONHECIMENTO ESCOLAR EM QUESTÃO}

Para que possamos produzir uma caracterização inicial do campo dos Estudos Curriculares, torna-se conveniente descrever e analisar alguns desafios, tanto de ordem teórica quanto epistemológica. Através do conhecido diálogo entre Garcia e Moreira (2003), podemos reconhecer que o conhecimento produzido nesse campo não é de natureza técnica e generalizável; no entanto, sua identidade tem fronteiras porosas e indefinidas. Em uma sistematização importante, Pacheco define que "a identidade dos estudos curriculares é um fator simultâneo de fragilização e consolidação" (2013, p. 449). Ao longo das últimas décadas, foram inúmeras as divergências, controvérsias e perspectivas que foram mobilizadas neste campo, favorecendo com que uma pluralidade disciplinar estivesse ocupada em examinar as variadas tradições do pensamento curricular.

No que tange aos desafios teóricos para o campo dos Estudos Curriculares, Pacheco (2013) sinaliza para a pluralidade identitária do campo, associando o currículo como dispositivo central da atividade educacional. De acordo com o autor, essa centralidade pode ser justificada "se currículo for sinónimo de conhecimento, pois não é possível falar de projeto de formação sem a inclusão de referências relativas a um corpus de saberes, valores, social e culturalmente reconhecido como válido" (p. 450). Enquanto derivado das Ciências da Educação, abarca questões vinculadas ao ensino, à aprendizagem e ao conhecimento. De forma abrangente, Pinar (2007) define que os Estudos Curriculares são "o estudo interdisciplinar da experiência educativa" (p. 18).

A questão estruturante do pensamento curricular vincula-se às dimensões sociais e epistemológicas do conhecimento a ser ensinado na escola. De acordo com Forquin (1993), "o pensamento pedagógico contemporâneo não pode se esquivar de uma reflexão sobre a questão da cultura e dos elementos culturais dos diferentes tipos de escolhas educativas, sob pena de cair na 
superficialidade" (p. 10). A seleção das experiências formativas da escola, então, materializa-se em saberes, competências, crenças, hábitos e valores que serão transmitidos para as gerações mais jovens (SILVA, 2016).

Isso significa dizer que a educação não transmite a cultura, considerada como um patrimônio simbólico unitário e imperiosamente coerente. Nem sequer diremos que ela transmite fielmente uma cultura ou culturas (no sentido dos etnólogos e dos sociólogos): ela transmite, no máximo, algo da cultura, elementos de cultura, entre os quais não há forçosamente homogeneidade, que podem provir de fontes diversas, ser de épocas diferentes, obedecer a princípios de produção e lógicas de desenvolvimento heterogêneos e não recorrer aos mesmos procedimentos de legitimação (FORQUIN, 1993, p. 15).

A partir dessa questão, vale assinalar que, quando nos propomos a analisar as articulações entre educação, formação e conhecimento, ingressamos em uma das questões mais emblemáticas do pensamento curricular. Reconhecemos, junto a Pacheco (2014), que a valorização do conhecimento não se constitui em uma novidade do nosso século - "a sociedade do conhecimento" -, mas trata-se de uma intensificação das construções pedagógicas erigidas na própria Modernidade (DUSSEL; CARUSO, 2003). Afastando-nos de uma perspectiva estritamente filosófica, é importante ponderar que o percurso do escolar "é a história desta operação em torno do conhecimento" (PACHECO, 2014, p. 7).

Diante desta condição, poderíamos justificar a pertinência e a atualidade do exame crítico das políticas que definem o que conta como conhecimento na escola.

Porque a escola define, cada vez mais, os percursos de formação que são trilhados, a questão do conhecimento é central para a discussão de políticas sociais, econômicas, culturais e educativas, não sendo possível alguém alhear-se, por um lado, da importância que as organizações educativas assumem na complexa tarefa da produção e transmissão do conhecimento e, por outro lado, do lugar de destaque do currículo, entendido, no sentido lato, como um projeto de formação, que traduz a organização, seleção e transformação do conhecimento em função de um dado espaço, de um determinado tempo e de acordo com propósitos educacionais (PACHECO, 2014, p. 7).

Acerca deste projeto de formação, é importante ressaltar que a definição do que conta como conhecimento na escola é sempre inscrita no campo da controvérsia (SACRISTÁN, 2013), visto que a sua validade deriva das condições históricas de seu tempo. Em outras palavras, o que conta como conhecimento escolar "é uma decisão que está em permanente debate, não sendo possível a existência de soluções meramente 'científicas' ou técnicas" (PACHECO, 2014, p. 8). Aprender mais ou estudar menos, por exemplo, são medidas difíceis de serem dimensionadas na contingência dos fazeres escolares.

As possibilidades de educação e formação, pela via do conhecimento, configuram-se como incontornáveis campos de reflexão (GABRIEL; CASTRO, 2013). Disso decorre a pertinência de manter o currículo sob permanente tensão e afastar-se de determinadas posturas que buscam retomar a "velha" ordem da escola.

\footnotetext{
A visão idealizada da escola enquanto guardiã do conhecimento universal desvanece-se e, em seu lugar, surge a escola ligada a problemas sociais, em que o conhecimento não é um ponto de chegada, mas um ponto de partida. Daí que as diferentes perspectivas de organização do currículo sejam formas de conceptualizar argumentos em torno do conteúdo da aprendizagem, com implicações quer no contexto organizacional, quer nos sujeitos, em função de diversos parâmetros discursivos entre sociedade, educação e formação (PACHECO, 2014, p. 8).
}

Junto a Pacheco, mais uma vez, podemos ponderar que o conhecimento ocupa uma posição central na organização da escola e de seus currículos; todavia, importante reconhecer que ele é derivado de uma escolha e que tal processo precisa ser permanentemente revisitado. Supõe-se também que "a escola e a formação sejam perspectivadas como projetos que ultrapassam a mera instrução" (p. 9). Nosso interesse, sob tal inspiração, requer uma crítica política dos processos de seleção do conhecimento escolar, impulsionada por uma atitude esperançosa de aposta no potencial formativo desta instituição. Em termos políticos, junto a Santos, poderíamos sinalizar que "talvez a originalidade no campo do 
currículo esteja na produção de discursos cujos significados possam oferecer alternativas para um cotidiano marcado pela superficialidade da propaganda e do consumo" $(2007$, p. 306).

Nos marcos de uma leitura crítica e criativa, duas dimensões merecem destaque ainda para este estudo teórico. A primeira delas refere-se a um alargamento conceitual da inovação educativa. Para um verbete elaborado para um dicionário especializado, Sancho-Gil e Hernandéz (2011) argumentaram que o século XX poderia ser caracterizado como o "século da inovação educativa, o século do desejo de mudança para melhorar, em princípio, os sistemas educativos" (p. 476). Entretanto, neste início de século XXI, Sancho-Gil diagnosticou a constituição de um "imperativo da inovação", operando nos variados níveis educacionais (2018, p. 15). Sua contribuição, bastante perspicaz e atual, defende a pertinência dos movimentos de inovação educativa, certamente pontuando os limites de inovar por modismos pedagógicos ou para seguir orientações das multinacionais que atuam no mercado digital.

A segunda dimensão, com ressonâncias para o conhecimento escolar, refere-se a uma intensificação das relações entre cidadania, democracia e aprendizagem (BIESTA, 2016). Ainda que cidadania e democracia não estejam em "perfeita reciprocidade" (BALIBAR, 2013), seria prudente, de acordo com Gert Biesta (2016), retomar a perspectiva de que "as práticas democráticas oferecem de fato importantes oportunidades de aprendizagem" (p. 33). A seleção e a organização de conhecimentos escolares, a partir desse ponto de vista, precisam ultrapassar a produção eficaz de resultados de aprendizagem (BIESTA, 2017) e direcionar-se na busca de novos modelos de "governança escolar democrática" (COLLET; TORT, 2016).

A combinação dessas dimensões - alargamento conceitual da inovação educativa e promoção de práticas curriculares mais democráticas - favorece o engendramento de novas fronteiras para o debate curricular contemporâneo. Sem desconsiderar o contexto que ora vivenciamos em que o neoconservadorismo se coloca em evidência nas políticas curriculares (VINAO, 2016; LIMA; HYPOLITO, 2019), na próxima seção examinaremos o entrelaçamento entre currículo, formação humana e a democracia visando aceitar seus desafios hodiernos, de maneira que não fragilizemos o processo formativo atinente à composição de uma escola democrática no Brasil.

\section{A QUESTÃO DA DEMOCRACIA: ELEMENTOS PARA UM DIAGNÓSTICO SOCIOLÓGICO}

Há quase duas décadas, Giddens (2000), na obra "Mundo em descontrole", sinalizava para um conjunto de paradoxos, por meio dos quais a democracia seria ou estava sendo experienciada no início do século XXI. Sua preocupação sociológica partia do pressuposto de que a democratização da democracia vinha assumindo contornos diferentes nos variados países e, ainda que parecesse o contrário, não poderíamos garantir que seu desenvolvimento seria progressivo e incontestável. Sob seu prisma, "um aprofundamento da democracia é necessário porque os velhos mecanismos de governo não funcionam numa sociedade em que os cidadãos vivem no mesmo ambiente de informação que os que detém poder sobre eles" (p. 84).

A metáfora explicativa com a qual Giddens expressa a atual situação da democracia é que se trata de uma "flor frágil", expressão que temos atribuído desde a epígrafe deste artigo. Tal metáfora se justifica pelo argumento de que, "apesar de sua difusão, os regimes opressivos abundam, enquanto direitos humanos são rotineiramente ludibriados em estados do mundo todo" (GIDDENS, 2000, p. 90). Em elaboração mais recente, Manuel Castells (2018) diagnosticou um cenário bem mais extremo: "a ruptura da relação entre governantes e governados" (p. 7). As quase duas décadas que distanciam as obras referidas permitem com que visualizemos não somente um declínio da democracia, mas sinais de sua ruptura. Nas palavras de Castells, "trata-se do colapso gradual de um modelo político de representação e governança: a democracia liberal que se havia consolidado nos dois últimos séculos, à custa de lágrimas, suor e sangue, contra os Estados autoritários e o arbítrio institucional" (2018, p. 8).

O modelo da democracia liberal, em suas variações, supunha tanto o primado das instituições coletivas quanto o direito e as liberdades individuais. A possibilidade de escolha dos governantes constituía-se como um elo importante dessa relação entre indivíduo e instituição e, mais do que isso, permitia o avanço em garantias políticas pela via da democracia, engendrada no próprio âmbito de sua legitimidade. A ruptura descrita por Castells expressa-se no desencanto pela vida pública e por um conjunto de mutações na vida social deste início de século. 
A luta pelo poder nas sociedades democráticas atuais passa pela política midiática, pela política do escândalo e pela autonomia comunicativa dos cidadãos. Por um lado, a digitalização de toda a informação e a interconexão modal das mensagens criaram um universo midiático no qual estamos permanentemente imersos (CASTELLS, 2018, p. 26).

Sem a pretensão de um retorno a um contexto democrático imaginário, Castells descreve como a política passa a ser mediada por outros instrumentos, ao mesmo tempo que declina sua confiança pública. Beck (2018), em obra póstuma, alertava para uma "metamorfose do mundo", contexto em que os indivíduos e as instituições transformavam seus horizontes de referência. De um prisma metodológico, Beck aponta que "para ser capaz de compreender essa metamorfose é necessário não apenas explorar a dissolução da realidade sócio-política, mas focar nos novos começos, naquilo que está emergindo e nas estruturas e normas futuras" (2018, p. 31).

Em outras palavras, o reconhecimento do declínio da democracia liberal precisa vir acompanhado de uma sensibilidade acerca da metamorfose em curso na vida social contemporânea. Ainda de acordo com o sociólogo, a metamorfose "desafia nosso modo de estar no mundo, de imaginar e fazer política" (2018, p. 36). Em termos educacionais, reconhecemos a pertinência de buscar por novos conceitos nesta realidade que se configura e - com maior ou menor intensidade - revisitar algumas de nossas ferramentas analíticas que foram sendo engendradas no decorrer das lutas pela escola democrática.

A busca por políticas e práticas curriculares democráticas no Brasil, então, percorreu um longo caminho, no qual poderíamos tomar como um dos pontos de partida o Manifesto dos Pioneiros da Educação Nova em 1932. Em muito inspirados pelo progressivismo pedagógico, em ampla difusão mundial, os signatários desse documento buscavam alternativas para a renovação educacional e para a reconstrução social. Postulavam uma preocupação em combater as formas tradicionais de educação, herdadas do Brasil Império, e, concomitantemente, propor uma centralidade da democracia, do método científico, da formação integral, do acesso à escola pública e do combate às desigualdades educacionais (SILVA, 2019). Em linhas gerais, face aos dilemas do século XX e da construção da República no Brasil, postulavam que "a educação nova não pode deixar de ser uma reação categórica, intencional e sistemática contra a velha estrutura do sistema educacional, artificial e verbalista, montada para uma educação vencida" (MANIFESTO, 2010 [1932], p. 40). Uma das referências fundamentais daquele período encontra-se na obra "Democracia e Educação", do filósofo estadunidense John Dewey, publicada originalmente em 1916.

Entretanto, conforme destacaremos no decorrer deste texto, inúmeras outras referências conceituais trouxeram contribuições específicas para o posterior debate brasileiro concernente à construção da escola democrática. Leituras ambivalentes (e muitas vezes antagônicas) foram delineando a perspectiva curricular crítica no Brasil: por vezes priorizando as experiências e as subjetividades dos estudantes (Teixeira); em outros momentos, priorizando os saberes e as práticas culturais (Freire) e também defendendo o conhecimento como uma ferramenta para a efetiva democratização da escolarização (Saviani). O progressivismo pedagógico no Brasil, no entanto, converge em pelo menos três aspectos, quais sejam: a) no enfrentamento da segregação do acesso à escola pública; b) na crítica à inorganização dos sistemas escolares brasileiros; c) na defesa de uma escola única para todos enquanto condição da vida democrática.

Em termos curriculares, parece-nos que esta agenda democrática - ainda em estado embrionário - foi sendo melhor desenvolvida pelos autores mencionados no decorrer do século XX. A preocupação com modos de vida democráticos acompanhou a literatura pedagógica brasileira desse período e favoreceu uma maior atenção a questões curriculares cruciais para o desenvolvimento de nossa proposição, como a ênfase na cidadania, a consideração dos saberes populares, a preocupação com a realidade dos estudantes, a difusão de mecanismos de escuta, os debates sobre as aprendizagens e o construtivismo pedagógico e os critérios para a seleção de conhecimentos escolares relevantes. Ainda que se referindo a outro contexto, Biesta (2017) aponta para a necessidade de se evitar o reducionismo a que "a produção eficaz de resultados de aprendizagem predefinidos" (p. 20) pode nos conduzir. Meirieu (2013), por sua vez, defende que retomemos a responsabilidade pedagógica por meio de três exigências, sejam elas: transmitir saberes emancipadores, compartilhar valores e formar para o exercício da democracia. Objetivamente, ao longo destas seções, procuramos descrever o cenário dos Estudos 
Curriculares (e dos modos de selecionar conhecimentos) em um contexto histórico no qual a condição democrática é colocada em xeque nos diferentes países. Apostamos em uma escola que seja capaz de inovar por meio do engendramento de práticas curriculares mais democráticas e, para isso, pretendemos buscar por traços conceituais na pedagogia brasileira do século XX. Na próxima seção, a partir de rápidas digressões históricas, buscaremos delinear uma agenda curricular democrática para a escola brasileira na contemporaneidade.

\section{PRÁTICAS CURRICULARES E ESCOLA DEMOCRÁTICA NO BRASIL}

Uma das preocupações que orientam a produção deste ensaio encontra-se nos modos pelos quais as práticas curriculares contemporâneas, ao se direcionarem para a inovação educativa, parecem negligenciar a questão da defesa da democracia. O debate curricular deste início de século XXI, sob nossa perspectiva, não pode abdicar da tarefa de reposicionar seus horizontes de referência, buscando revitalizar os pressupostos democráticos que foram construídos na pedagogia brasileira em meados do último século. A promoção de oportunidades educativas aos estudantes, a dialogicidade como conteúdo e método e a opção por conhecimentos escolares relevantes serão os traços conceituais que buscaremos para colocar em discussão no presente estudo. A inovação educativa que se deriva deste cenário diz respeito à mobilização da escola na busca por uma "governança escolar democrática", como recentemente esboçaram Jordi Collet e Antoni Tort (2016).

Antes de avançarmos na composição de nossas análises, importante sinalizar os três pressupostos que orientaram nossos estudos: 1) A busca pela governança democrática pode se constituir como um dispositivo orientador para a defesa de conhecimentos escolares relevantes no currículo escolar (COLLET; TORT, 2016). 2) Uma escola democrática possui uma agenda formativa aberta, constituindose como efetiva comunidade colaborativa (BEANE, 2017). 3) Uma escola justa e democrática, como uma agenda formativa aberta, atribui centralidade aos movimentos de inovação educativa, tomando-os como um processo de "agitação intelectual permanente" (CARBONELL, 2017). Articular tais dimensões torna-se importante para este ensaio.

Todavia, do ponto de vista metodológico, escolhemos examinar essas articulações entre escola democrática e inovação educativa nos escritos pedagógicos brasileiros de meados do século XX. A seu modo, Anísio Teixeira, Paulo Freire e Demerval Saviani contribuíram decisivamente para o delineamento do progressivismo pedagógico no Brasil e, por diferentes caminhos e inúmeras controvérsias, contribuíram para a defesa de uma escola democrática em nosso país. Seus contrapontos ao modelo organizativo herdado da tradição passavam pela defesa da escola pública para todos - laica, gratuita e obrigatória. Sob um prisma curricular, aquele que acompanha as nossas preocupações, destacaremos neste estudo três princípios para a forma curricular que se deriva desses pensadores, quais sejam: a promoção de oportunidades, a dialogicidade como conteúdo e método e a opção pelos conhecimentos socialmente relevantes. Importante, aqui, uma ressalva: reconhecemos que os referidos autores escreveram suas obras a partir dos desafios do seu tempo; assim, nossa intenção não se vincula a uma transcrição direta para explicar a escola do século XXI - apenas um reconhecimento de que seu pensamento ainda apresenta significativo potencial heurístico. A seguir, examinaremos cada um destes princípios, tomando-os como vetores para práticas curriculares democráticas e inovadoras neste início de século.

\section{Práticas curriculares e a promoção de oportunidades aos estudantes}

Quando nos colocamos a analisar o pensamento pedagógico progressista no Brasil, especialmente no que concerne às questões curriculares, encontramos uma entrada importante nos textos escritos por Anísio Teixeira, um dos principais intelectuais brasileiros da primeira metade do século XX que, sob a influência do pensamento de John Dewey, difundiu pelo País as bases teóricas para uma escola democrática. Em um pequeno manual de filosofia da educação, cuja primeira edição data do fim da década de 1930, Teixeira expõe objetivamente a sua percepção do progressivismo e, à luz do Manifesto dos Pioneiros da Educação Nova, reflete sobre a transformação escolar. Em termos curriculares, sua preocupação encontrava-se na centralidade da criança, na reconstrução dos programas escolares e da organização psicológica das matérias escolares. 
Nas condições do contexto brasileiro, o progressivismo difundido por Teixeira estabelecia como tarefa pública a defesa da escola para todos. Em sua acepção, "a escola progressiva é a escola onde as atividades se processam com o máximo de oportunidades para essa ascensão" (TEIXEIRA, 1978, p. 23). O desenvolvimento de oportunidades para que os indivíduos progredissem alicerçava-se em um ambiente estimulante, em atividades sequenciadas e em experiências que exigissem esforço. Merece atenção, em suas teorizações, a posição a ser ocupada pelos professores, mesmo reconhecendo a centralidade da criança.

Sob inspiração do progressivismo estadunidense, Teixeira reconhecia a importância de a escola se adaptar às demandas sociais, sobretudo àquelas derivadas das mudanças em curso na economia, na política e na ciência. Apregoava a necessidade de uma escola renovada que buscasse se reposicionar frente a esses novos desafios civilizatórios.

Nessa nova ordem de mudança constante e de permanente revisão, duas coisas ressaltam que
alteram profundamente o conceito da velha escola tradicional:
a) precisamos preparar o homem para indagar e resolver por si os seus problemas;
b) temos que construir a nossa escola, não como preparação para um futuro desconhecido, mas
para um futuro rigorosamente imprevisível (TEIXEIRA, 1978, p. 30).

A superação da escola tradicional apresentava-se como um imperativo para os modos de vida requeridos pelo século que se iniciava. A ciência, a indústria e a democracia - como exigências do mundo moderno em que o Brasil almejava ingressar - ofereciam possibilidades de transformação da escola brasileira; isso, segundo o pensador, correspondia a ampliar e qualificar as discussões sobre as finalidades públicas da escolarização. Segundo Teixeira (1978), em uma elaboração sintética, a finalidade da escola seria "ajudar os nossos jovens, em um meio social liberal, a resolver os seus problemas, morais e humanos" (p. 41).

Em termos curriculares, a primeira grande contribuição que Teixeira herda do progressivismo estadunidense e difunde no Brasil é a concepção da criança como centro da escola. Mesmo reconhecendo alguns possíveis "excessos" no uso deste princípio, o autor dispõe que o mais importante é compreender "a tendência central da renovação escolar: o respeito pela individualidade infantil” (TEIXEIRA, 1978, p. 55). Valorizar as diferenças individuais, priorizar os interesses infantis e educar por meio de experiências - principalmente utilizando metodologias em que as crianças sejam ativas - são pressupostos defendidos pelo autor e percebidos como desafiadores da escola tradicional (e de sua incapacidade de responder aos dilemas brasileiros para o futuro).

Corolário imediato de uma escola de experiência e de vida é que os alunos sejam ativos. Em vez da velha escola de ouvir, a nova escola de atividade e de trabalho. Não basta, porém, que os alunos sejam ativos. É necessário que eles escolham as suas atividades. Vimos o papel que tem na aprendizagem o intento, o propósito e o interesse do aluno. Se só se aprende o que sucede ou o que satisfaz aquilo que a criança entende, em cada caso, como sucesso, é sumamente importante (TEIXEIRA, 1978, p. 48-49).

Para a mudança da escola brasileira, de maneira que corresponda a este novo perfil de estudante, uma diretriz importante destacada por Anísio Teixeira refere-se aos programas escolares. A reconstrução dos programas - tomando-se as experiências como eixos estruturantes - promoveria uma maior aproximação da escola com a vida. Inspirado nos escritos deweyanos, Teixeira defendia que "a escola deve ser uma parte integrada da própria vida, ligando as suas experiências às experiências de fora da escola" (p. 59). Distanciando-se dos currículos formalizados nos livros e transmitidos aos estudantes, a preocupação localiza-se em centrar-se no "aprender".

O programa escolar que se derivaria dessas diretrizes, de acordo com Teixeira, seria constituído por "uma série de experiências e atividades em que a criança se vai empenhar na escola" (p. 62). O currículo, então, seria um conjunto de atividades educativas em que as crianças teriam a oportunidade de progredir, sendo os conteúdos extraídos das experiências acumuladas pela humanidade e selecionadas pela criança a partir de seus interesses.

A unidade constitutiva do programa escolar é a atividade aceita pelo aluno e por ele devidamente planejada. As atividades devem ser tais, que levem os alunos à aprendizagem dos conhecimentos, 
hábitos e atitudes indispensáveis para resolver os problemas de sua própria vida. O papel do professor está em despertar os problemas, torná-los sentidos ou conscientes, dar-lhes uma sequência organizada e prover os meios necessários para que os alunos os resolvam, de acordo com o melhor método e o melhor conhecimento (TEIXEIRA, 1978, p. 65).

Por fim, após defender a centralidade da criança e a necessária reconstrução dos programas escolares, Teixeira propõe que as matérias escolares recebam uma organização psicológica. Em termos curriculares, considerando sua leitura do progressivismo estadunidense para o contexto brasileiro, sua preocupação era que tais matérias fossem centradas nas experiências (não nos resultados) e "incidissem [sobre] o inquérito, a reflexão, o estudo, no desenvolvimento de uma determinada atividade" (p. 68). Decorre, desse ponto, sua defesa de que o currículo escolar fosse organizado em "unidades de trabalho" (ou projetos), capazes de mobilizar o desejo de aprender das crianças.

Para tanto, Teixeira defendia uma organização psicológica dos conhecimentos a serem ensinados, distanciando-se dos modelos "lógicos" que predominavam na escola tradicional.

\begin{abstract}
As matérias escolares passarão, aí, do seu lugar de honra para o de simples servas do crescimento infantil, contribuindo para ele quando chamadas. A organização lógica dará lugar às organizações psicológicas pessoais dos conhecimentos adquiridos. Além dessa obra escolar, incentive o professor as atividades extraclasses. Dê liberdade aos alunos para organizar a sua vida social e recreativa. Estimule-os neste exercício de autonomia e de responsabilidade (TEIXEIRA, 1978, p. 83).
\end{abstract}

As elaborações conceituais de Anísio Teixeira contribuíram para que pudéssemos levar adiante práticas curriculares com foco no desenvolvimento das capacidades das crianças e adolescentes. Suas compreensões do papel da ciência e da democracia, derivadas do pragmatismo deweyano, foram amplamente difundidas no Brasil, contribuindo para uma crítica política da escola livresca que havíamos herdado do período imperial. Acrescenta-se, ainda, a partir de sua experiência brasileira, a preocupação com as desigualdades e com o enfrentamento da compreensão da educação como um privilégio. Centrarse no aprendente e em sua capacidade de ação torna-se fundamental.

\title{
Práticas curriculares e a dialogicidade como conteúdo e método
}

Uma vez que buscamos descrever a emergência do progressivismo pedagógico no Brasil, particularmente rastreando suas perspectivas curriculares, neste momento direcionaremos nossa reflexão para a década de 1960, por meio dos reconhecidos escritos de Paulo Freire. Na obra "Pedagogia do Oprimido", podemos encontrar significativos pressupostos curriculares que tiveram uma indelével contribuição na construção de uma escola progressista no Brasil, na segunda metade do século passado. Nesta seção, buscaremos colocar em evidência alguns traços conceituais do pensamento freireano.

Em termos epistemológicos, Freire justifica sua pedagogia do oprimido baseando-se nas possibilidades da radicalização, distanciando-se do que nomeia como uma "atitude de sectarização". Em seu ponto de vista, comprometido com os debates progressistas que ocorriam na América Latina, era necessário reconstruir o pensamento crítico na direção da libertação.

É que a sectarização é sempre castradora, pelo fanatismo de que se nutre. A radicalização, pelo contrário, é sempre criadora, pela criticidade que a alimenta. Enquanto a sectarização é mítica, por isto alienante, a radicalização é crítica, por isto libertadora. Libertadora porque, implicando o enraizamento que os homens fazem na opção que fizeram, os engaja cada vez mais no esforço de transformação da realidade concreta, objetiva (FREIRE, 1987, p. 25).

A opção pela criticidade que a atitude revolucionária lhe proporcionava era justaposta, no âmbito do pensamento freireano, à necessidade de apostar na humanização. A hipótese antropológica de que somos seres inconclusos conduzia a pensar a condição humana nos termos da relação existente entre humanização e desumanização, envolvendo-se na superação da contradição entre opressores e oprimidos. Sob este cenário, Freire defenderá que "lutando pela restauração de sua humanidade estarão, sejam homens ou povos, tentando a restauração da generosidade verdadeira” (p. 31). A referida luta, em 
busca da superação da ordem social injusta, coloca-se no horizonte de uma pedagogia humanista e crítica que se deriva dos escritos freireanos.

Em termos pedagógicos, a primeira aposta delineada na obra referia-se à liberdade. Para tanto, no âmbito da relação entre opressores e oprimidos, sua crítica encontrava-se inicialmente na prescrição. Toda prescrição, em suas palavras, "é a imposição da opção de uma consciência a outra. Daí o sentido alienador das prescrições que transformam a consciência recebedora no que vimos chamando de consciência 'hospedeira' da consciência opressora" (FREIRE, 1987, p. 34). A superação da prescrição, de forma objetiva, ampliaria as possibilidades de conquista da liberdade pelos oprimidos.

Nesse ponto, deparamo-nos com algumas premissas do pensamento de Freire que apresentam significativas derivações curriculares. A primeira premissa que destacaremos se refere à necessidade de inserção crítica dos oprimidos na realidade dos opressores e, consequentemente, suas possibilidades de ação transformadora. No vocabulário pedagógico delineado por Freire, "práxis" é o conceito que articula as dimensões da reflexão e da ação.

Desta forma, esta superação exige a inserção crítica dos oprimidos na realidade opressora, com que, objetivando-a, simultaneamente atuam sobre ela. Por isto, inserção crítica e ação já são a mesma coisa. Por isto também é que o mero reconhecimento de uma realidade que não leve a esta inserção crítica (ação já) não conduz a nenhuma transformação da realidade objetivamente, precisamente porque não é reconhecimento verdadeiro (FREIRE, 1987, p. 38).

Derivada da noção de práxis, a segunda premissa que escolhemos retomar é a dimensão política da pedagogia do oprimido. Explica o pensador brasileiro que as pedagogias e os modos de organização das escolas se basearam, historicamente, em "narração de conteúdos". Ao se distanciarem dos contextos de vida dos oprimidos, tais práticas escolares "tendem a petrificar-se ou a fazer-se algo quase morto, sejam valores ou dimensões concretas da realidade" (p. 57). A narração de conteúdos serve de base para a conhecida metáfora - "educação bancária". Nesta crítica, consolida-se uma reação à "narração" como instrumento central da aula, associada à memorização mecânica ou passiva pelos estudantes.

Em termos curriculares, Freire busca superar a concepção bancária da educação e os modos de organizar os saberes dela derivados.

\footnotetext{
Na visão 'bancária' da educação, o 'saber' é uma doação dos que se julgam sábios aos que julgam nada saber. Doação que se funda numa das manifestações instrumentais da ideologia da opressão - a absolutização da ignorância, que constitui o que chamamos de alienação da ignorância, segundo a qual esta se encontra sempre no outro. O educador, que aliena a ignorância, se mantém em posições fixas, invariáveis. Será sempre o que sabe, enquanto os educandos serão sempre os que não sabem. A rigidez destas posições nega a educação e o conhecimento como processos de busca (FREIRE, 1987, p. 58).
}

A crítica ao ato de depositar, como metáfora explicativa das práticas de escolarização, vem acompanhada de um conjunto de proposições e alternativas possíveis na direção de uma educação problematizadora. Nesse ponto, podemos anunciar a terceira premissa do pensamento freireano para $\mathrm{O}$ currículo brasileiro no século XX, qual seja: a dialogicidade como princípio e como método para uma escola renovada. Com outras intencionalidades formativas, a educação problematizadora reconstrói-se na práxis, na crítica aos modelos transmissivos e conecta-se com as culturas vividas pelos estudantes e pelo universo simbólico de suas experiências.

A educação problematizadora, de acordo com Freire, enaltece que o diálogo começa na própria busca dos conhecimentos a serem ensinados. O diálogo, nesta direção, toma como ponto de partida o mapeamento dos temas geradores que serão estudados coletivamente e direciona-se para uma crítica política que permita desvendar alternativas de transformação.

O importante, do ponto de vista de uma educação libertadora, e não "bancária", é que, em qualquer dos casos, os homens se sintam sujeitos de seu pensar, discutindo o seu pensar, sua própria visão de mundo, manifestada implícita ou explicitamente nas suas sugestões e nas de seus companheiros. Porque esta visão da educação parte da convicção de que não pode sequer presentear o seu programa, mas tem de buscá-lo dialogicamente com o povo, é que se inscreve 
como uma introdução à pedagogia do oprimido, de cuja elaboração deve ele participar (FREIRE, 1987, p. 120).

Seriam inúmeras as perspectivas curriculares que poderiam decorrer do pensamento freireano. Escolhemos abordar a questão da dialogicidade reconhecendo o seu potencial pedagógico para pensar sobre as condições democráticas para uma inovação educativa. Uma escola renovada, em Freire, passaria pela sua capacidade de romper as relações dicotômicas entre sujeitos e objetos, educadores e educandos e entre escola e vida. Tais práticas curriculares seriam culturalmente referenciadas e distanciarse-iam das abordagens narrativas do conhecimento - tal princípio, em nossa perspectiva, ampliaria as possibilidades de uma inovação educativa movida por uma agenda aberta e democrática.

\section{Práticas curriculares e a opção pelos conhecimentos socialmente relevantes}

Outra vertente do progressivismo pedagógico engendrado no Brasil, no fim da década de 1970, produziu uma releitura do pensamento crítico, especialmente os escritos políticos de Antonio Gramsci. Esta perspectiva coaduna-se com as anteriores por meio de seu posicionamento em favor da democracia; todavia, ao repensar as relações entre educação e sociedade, redefine a problemática em favor dos conhecimentos historicamente elaborados e a sua garantia para as camadas pobres da população. Em seu livro "Escola e Democracia", um dos textos fundadores desta tradição (desses princípios), Demerval Saviani (2009 [1983]) compila alguns dos principais pressupostos pedagógicos (e curriculares) dessa tradição, os quais ampliaremos a partir deste momento.

Seu ponto de partida, em interlocução com a sociologia latino-americana da segunda metade do século XX, encontra-se no debate sobre o "problema da marginalidade". Considerando as amplas camadas da população que se mantinham marginalizadas, Saviani apregoava a necessidade de pensar a educação como "um instrumento de correção destas distorções" (2009, p. 4). O autor brasileiro revisita as correntes pedagógicas predominantes no Brasil - dos escolanovistas aos tecnicistas - para, em linhas gerais, esboçar novas perspectivas para uma teoria crítica da educação. Em um exercício de síntese, formula a seguinte interrogação, que serve como orientação geral para esta perspectiva: "é possível uma teoria da educação que capte criticamente a escola como um instrumento capaz de contribuir para a superação do problema da marginalidade?” (SAVIANI, 2009, p. 28).

A teorização crítica que advém dessa preocupação se distancia das abordagens reprodutivistas, bastante em voga na década de 1980. Saviani reitera a potencialidade política de lutar contra a seletividade presente na educação das camadas populares.

Lutar contra a marginalidade por meio da escola significa engajar-se no esforço para garantir aos trabalhadores um ensino da melhor qualidade possível nas condições históricas atuais. O papel de uma teoria crítica da educação é dar substância concreta a essa bandeira de luta de modo a evitar que ela seja apropriada e articulada com os interesses dominantes (SAVIANI, 2009, p. 29).

Sob tal bandeira, ainda na obra "Escola e Democracia", o pesquisador brasileiro visa distanciar-se dos modelos centrados na noção de educação compensatória. Em seu prisma, tal forma escolar, na América Latina, "configura uma resposta não-crítica às dificuldades educacionais postas em evidência pelas teorias crítico-reprodutivistas" (SAVIANI, 2009, p. 30). A busca por uma escola democrática, sob essa argumentação, ultrapassaria a lógica de mera compensação, visto que sua intencionalidade era o aprimoramento do ensino oferecido às pessoas pobres. Tal aprimoramento, de acordo com Saviani, materializava-se na "prioridade aos conteúdos" (p. 50).

Para a garantia de práticas democráticas, os conhecimentos ocupavam um lugar central no currículo. Conforme a exposição do autor, "os conteúdos são fundamentais e sem conteúdos relevantes, conteúdos significativos, a aprendizagem deixa de existir, ela transforma-se num arremedo, ela transforma-se numa farsa" (SAVIANI, 2009, p. 50). Mais do que isso, a luta pela democratização do acesso aos conteúdos configura-se como uma questão central nesta abordagem crítica.

Parece-me, pois, fundamental que se entenda isso e que, no interior da escola, nós atuemos segundo essa máxima: a prioridade de conteúdos, que é a única forma de lutar contra a farsa do ensino. Por que esses conteúdos são prioritários? Justamente porque o domínio da cultura 
constitui instrumento indispensável para a participação política das massas (SAVIANI, 2009, p. $50)$.

A vinculação entre o domínio de determinados conhecimentos e as condições para o exercício da cidadania configura-se como central nesta perspectiva teórica. As práticas curriculares derivadas desses pressupostos propõem-se a enfrentar as desigualdades no acesso ao saber universal, reconhecendo que "a importância da transmissão de conhecimentos, de conteúdos culturais, marca distintiva da pedagogia da essência, não perde seu caráter revolucionário" (SAVIANI, 2009, p. 58). Para além da difusão de métodos inovadores ou da valorização cultural dos estudantes, sob esta abordagem, a pedagogia crítica não pode abdicar da oferta de ferramentas intelectuais para a compreensão e a transformação do presente.

Esta perspectiva defende ainda que a importância política da educação reside na sua função de socialização de conhecimento. Por meio de uma inspiração gramsciana, a educação torna-se política quando promove a igualdade no acesso a determinados saberes e, em termos curriculares, reinveste o conhecimento de sentidos democráticos.

Para isso, a pedagogia revolucionária, longe de secundarizar os conhecimentos descuidando de sua transmissão, considera a difusão de conteúdos, vivos e atualizados, uma das tarefas primordiais do processo educativo em geral e da escola em particular (SAVIANI, 2009, p. 59).

Com os escritos de Saviani, conseguimos observar a emergência de uma escola democrática que se preocupa com o acesso a conhecimentos escolares relevantes. A educação crítica que se estabelece, segundo esse modo de abordagem, aceita a difusão de novos métodos ou o primado das referências culturais dos estudantes; todavia, acrescenta que, sem as devidas ferramentas intelectuais que provenham dos saberes especializados, as comunidades populares seguirão em posição de subalternidade. As práticas curriculares inspiradas nesta tradição reconstroem a inovação educativa com sentidos sociais e políticos voltados para a socialização do conhecimento.

\section{CONSIDERAÇÕES FINAIS}

Ao longo do presente estudo, procuramos mapear os modos pelos quais as obras de Anísio Teixeira, Paulo Freire e Demerval Saviani (ainda) apresentam potencial heurístico não somente para interpretar a escola contemporânea, mas, também, para contribuir na construção de uma agenda curricular democrática com foco na inovação educativa. Em termos curriculares, a abordagem construída neste ensaio atribui centralidade para um alargamento conceitual da inovação educativa justaposto aos marcos de uma governança escolar democrática. Ao enfocarmos a questão da inovação, de acordo com Carbonell (2017), faz-se importante considerar que esta se movimenta entre processos de melhoria e de transformação institucional. Em sua abordagem, implica reconhecer que precisamos mudar a escola com diferentes graus de radicalidade -, as dimensões como "os conteúdos do currículo, os modos de ensinar e aprender e a participação dos distintos atores da comunidade educativa" (p. 77).

Associa-se a isso, desde uma perspectiva curricular, nossa preocupação com o agenciamento de diferentes formas de "governança escolar democrática" (COLLET; TORT, 2016). Ao "repolitizar a educação", o debate conceitual proposto pelos pesquisadores espanhóis amplia nossas ferramentas para o questionamento, a reflexão e a prática de uma educação que se contrapõe aos modelos neoliberal e neoconservador, hoje predominantes (BALL, 2016; VIÑAO, 2016). Ao mesmo tempo, mais uma vez recorrendo a Biesta (2017), ele pode permitir que desnaturalizemos a aprendizagem e possamos reinscrevê-la em um território político. A promoção de oportunidades, a dialogicidade como conteúdo e método e a seleção de conhecimentos relevantes, práticas que herdamos da pedagogia brasileira do século $\mathrm{XX}$, apresentam-se como alternativas possíveis para defendermos outra "flor frágil" - a escola democrática!

\section{REFERÊNCIAS}


BALIBAR, Étienne. Ciudadanía. Buenos Aires: Adriana Hidalgo Editora, 2013.

BALL, Stephen. Gobernanza neoliberal y democracia patológica. In: COLLET, Jordi; TORT, Antoni. (Orgs.). La gobernanza escolar democrática. Madrid: Morata, 2016, p. 23-40.

BEANE, James. Ensinar em prol da democracia. Revista e-Curriculum, v. 15, n. 4, p.1050-1080, 2017.

BECK, Ulrich. A metamorfose do mundo: novos conceitos para uma nova realidade. Rio de Janeiro: Zahar, 2018.

BIESTA, Gert. Medir lo que valoramos o valorar lo que medimos? - globalización, responsabilidad y la noción de propósito de la educación. Pensamiento educativo, v. 51, n. 1, p. 46-57, 2014.

BIESTA, Gert. Para além da aprendįagem: educação democrática para um futuro humano. Belo Horizonte: Autêntica, 2013.

BIESTA, Gert. Devolver la enseñanza a la educación: una respuesta a la desaparición del maestro. Pedagogía y Saberes, n. 44, p. 119-129, 2016.

BIESTA, Gert. El bello riesgo de educar. Madrid: Ediciones SM, 2017.

CARBONELL-SEBARROJA, Jaume. Las pedagogías inovadoras y las visiones de los contenidos. In: SACRISTÁN, José Gimeno (Org.). Los contenidos: una reflexión necesaria. Madrid: Morata, 2017, p. 7782.

CASTELLS, Manuel. Ruptura: a crise da democracia liberal. Rio de Janeiro: Zahar, 2018.

COLLET, Jordi; TORT, Antoni (Orgs.). La gobernanza escolar democrática. Madrid: Morata, 2016.

DUSSEL, Inés; CARUSO, Marcelo. A invenção da sala de aula: uma genealogia das formas de ensinar. São Paulo: Moderna, 2003.

FORQUIN, Jean-Claude. Escola e cultura: as bases sociais e epistemológicas do conhecimento escolar. Porto Alegre: Artes Médicas, 1993.

FREIRE, Paulo. Pedagogia do oprimido. 17a ed. São Paulo: Paz e Terra, 1987.

FULLAN, Michael. El significado del cambio educativo: un cuarto de siglo de aprendizaje. Profesorado, revista de curriculum y formación del professorado, v. 6, n. 1-2, p. 1-14, 2002.

GABRIEL, Carmen; CASTRO, Marcela. Conhecimento escolar: objeto incontornável da agenda política educacional contemporânea. Educação em Questão, v. 45, n. 31, p. 82-110, 2013.

GARCIA, Regina; MOREIRA, Antonio Flávio. Começando uma conversa sobre currículo. In: GARCIA, Regina; MOREIRA, Antonio Flávio (Orgs.). Currículo na contemporaneidade: incertezas e desafios. São Paulo: Cortez, 2003.

GIDDENS, Anthony. Mundo em descontrole: o que a globalização está fazendo de nós. Rio de Janeiro: Record, 2000.

LIMA, Iana Gomes de; HYPOLITO, Álvaro Moreira. A expansão do neoconservadorismo na educação brasileira. Educaşão e Pesquisa, v. 45, e190901, 2019. 
MANIFESTO. Manifesto dos Pioneiros da Educaşão Nova (1932) e dos Educadores (1959). Recife: Fundação Joaquim Nabuco/Editora Massangana, 2010.

MARCELO, Carlos. Las tecnologías para la innovación y la práctica docente. Revista Brasileira de Educação, v. 18, n. 52, p. 25-47, 2013.

MEIRIEU, Philippe. La opción de educar y la responsabilidad pedagógica. Buenos Aires: Ministerio de Educación, 2013.

MOREIRA, Antonio Flávio. Os princípios norteadores de políticas e decisões curriculares. Revista Brasileira de Politica e Administração Educacional, v. 28, n. 1, p.180-194, 2012.

PACHECO, José Augusto. Educaşão, formação e conhecimento. Porto: Porto Editora, 2014.

PACHECO, José Augusto. Estudos curriculares: desafios teóricos e metodológicos. Ensaio, v. 21, n. 80, p. 449-472, 2013.

PINNAR, William. O que é a teoria do currículo? Porto: Porto Editora, 2007.

POPKEWITZ, Thomas. El cosmopolitismo y la era de la reforma escolar. Madrid: Morata, 2009.

SACRISTÁN, José Gimeno. O que significa o currículo?. In: SACRISTÁN, José Gimeno (Org.). Saberes e incertezas sobre o currículo. Porto Alegre: Penso, 2013, p. 16-35.

SANCHO-GIL, Juana; HERNANDEZ, Fernando. Inovação educativa. In: VAN ZANTEN, Agnes (Coord.). Dicionário de Educação. Petrópolis: Vozes, 2011, p. 476-481.

SANCHO-GIL, Juana. Innovación y enseñanza: de la "moda" de innovar a la transformación de la practica docente. Educação (PUCRS), v. 41, n. 1, p. 12-20, 2018.

SANTOS, Lucíola. Currículo em tempos difíceis. Educação em Revista, v. 45, p. 291-306, 2007.

SAVIANI, Dermeval. Escola e democracia. 41a ed. Campinas: Autores Associados, 2009.

SILVA, Roberto Rafael Dias da. Customização curricular no Ensino Médio: elementos para uma crítica pedagógica. São Paulo: Cortez, 2019.

SILVA, Roberto Rafael Dias da. Currículo, conhecimento e transmissão cultural: contribuições para uma teorização pedagógica contemporânea. Cadernos de Pesquisa, v. 46, n. 159, p. 158-182, 2016.

TEIXEIRA, Anísio. Pequena introdução à filosofia da educação: a escola progressiva ou a transformação da escola. 7a ed. São Paulo: Companhia Editora Nacional, 1978.

TYACK, D.; CUBAN, L. En busca de la utopía. Un siglo de reformas en las escuelas públicas. México: Fondo de Cultura Económica, 2001.

VEIGA-NETO, Alfredo. De geometrias, currículo e diferenças. Educação e Sociedade, n. 79, p. 163-186, 2002.

VIÑAO, Antonio. Culturas escolares y reformas (sobre la naturaleza histórica de los sistemas e instituciones educativas). Teias, v.1, n. 2, p. 1-25, 2000. 
VIÑAO, Antonio. El modelo neoconservador de gobernanza escolar: princípios, estratégias y consecuencias en España. In: COLLET, Jordi; TORT, Antoni (Orgs.). La gobernanza escolar democrática. Madrid: Morata, 2016, p. 41-64.

Submetido: $02 / 10 / 2020$

Aprovado: 05/01/2021 